\title{
Participação Cidadã no contexto da internet: um estudo sobre o uso de mídia social por lideranças comunitárias na região centro- oeste do Rio Grande do Sul, Brasil
}

\author{
Citizen participation in the context of internet: a study on the use of social \\ media by community leaders in the central-western region of Rio Grande do \\ Sul, Brazil
}

\section{Participación Ciudadana en el contexto de Internet: un estudio sobre el uso de medios sociales por líderes comunitarios en la región centro-oeste de Rio Grande do Sul, Brasil}

\author{
Adriane Roso ${ }^{1}$ \\ Sandra Rúbia da Silva
}

\begin{abstract}
Resumo
Buscando adensar as reflexões no campo de Estudos da Cultura Material, esse artigo relata parte de uma pesquisa de pós-doutorado. A partir de um delineamento etnográfico, o objetivo geral foi entender os impactos sociais da apropriação da internet por líderes comunitários. A pesquisa foi desenvolvida em uma comunidade no sul do Brasil. Durante 11 meses, a rede social Facebook de um líder comunitário e sua esposa foi seguida. Especificamente, intencionou-se analisar as postagens relacionadas a questões comunitárias com o intento de identificar elementos relacionados à participação cidadã. Entre outros aspectos, foi encontrado que o Facebook é um espaço que possibilita a participação cidadã. Concluiu-se que o Facebook foi utilizado especialmente como uma ferramenta política, ainda que essa participação esteja diretamente vinculada à arena privada.
\end{abstract}

\begin{tabular}{|c|c|}
\hline \multirow{3}{*}{ 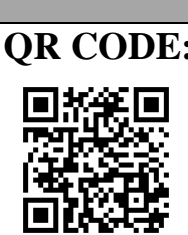 } & Acesse este artigo online \\
\hline & $\begin{array}{l}\text { Website: } \\
\text { http://www.revistas.ufg.br/index.php/ci }\end{array}$ \\
\hline & $\begin{array}{l}\text { DOI: } \\
\text { http://dx.doi.org/10.5216/ci.v19i2.38857 }\end{array}$ \\
\hline
\end{tabular}

Palavras-Chave: Cultura material. Consumo. Internet. Participação Cidadã.

\begin{abstract}
Seeking to deepen the reflections on the Material Culture Studies field, this paper reports part of a post-doctoral research. Within an ethnographic design, the main objective was to better understand the social impacts of the Internet appropriation of community leaders. The research was carried on in a community located in South Brazil. During 11 months, the social network profile Facebook of a community leader and his wife was followed. Specifically it was intended to analyze the posts related to community issues in order to identify elements regarding citizen participation. Among other
\end{abstract}

\footnotetext{
1 Doutora em Psicologia na Pontifícia Universidade Católica do Rio Grande do Sul. Pós-Doutora em Comunicação na Universidade Federal de Santa Maria. Docente do Programa de Pós-graduação em Psicologia da UFSM Universidade Federal de Santa Maria, Rio Grande do Sul, Santa Maria, Brasil. Bolsista de Produtividade em Pesquisa do CNPq. E-mail: psicosocial.ufsm@gmail.com

Doutora em Antropologia Social pela Universidade Federal de Santa Catarina. Docente do Programa de Pós-Graduação em Comunicação da UFSM - Universidade Federal de Santa Maria. Brasil, Rio Grande do Sul, Santa Maria. E-mail: sandraxrubia@gmail.com
}

Comun. \& Inf., Goiânia, GO, v. 20, n. 1, p. 92-114, jan./jun. 2017 
findings, it was found that the Facebook is a space that turns out possible the citizen participation. It was concluded that Facebook is specially used as a political tool, even if such participation is directly linked to the private arena.

Keywords: Material culture. Consume. Internet. Citizen Participation.

\section{Resumen}

En este artículo relata parte de una investigación de postdoctorado, que busca adensar las reflexiones en el campo de Estudios de la Cultura Material. A partir de un delineamiento etnográfico, el objetivo general fue entender los impactos sociales de la apropiación de Internet por líderes comunitarios. La investigación fue desarrollada en una comunidad en el sur de Brasil. Durante 11 meses, el perfil en la red social Facebook de un líder comunitario y de su esposa fue seguido. Específicamente, se ha intentado analizar los planteamientos relacionados con cuestiones comunitarias con el propósito de identificar elementos relacionados a la participación ciudadana. Entre otros aspectos, se ha encontrado que Facebook es un espacio que permite la participación ciudadana. Se concluyó que Facebook fue utilizado especialmente como una herramienta política, aunque esta participación está directamente vinculada a la arena privada.

Palabras clave: Cultura material. Consumo. Internet. Participación Ciudadana.

\section{INTRODUÇÃO}

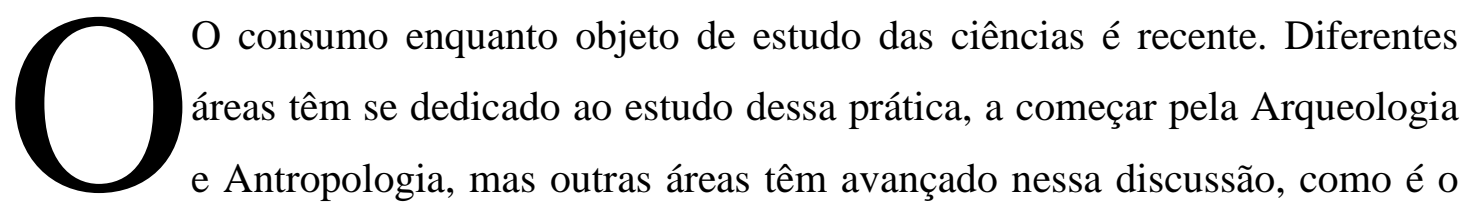
caso da Psicologia Social ${ }^{3}$ e da Comunicação, áreas onde se inserem a primeira autora deste artigo e a segunda, respectivamente. Nessas áreas, há diferentes perspectivas para se aproximar desse objeto de estudo. Grosso modo, é possível indicar duas perspectivas salientes nos estudos do consumo: a perspectiva anti-material (ligada à produção em série), na qual grande parte dos estudos da Psicologia Social se insere, e a perspectiva material (voltada às práticas de consumo), mais ligada aos estudos da comunicação e é sob esta perspectiva que desenvolveremos nosso objeto de estudo.

Consumo é uma categoria central na definição da sociedade contemporânea que diz respeito a múltiplas formas de provisão de bens e serviços e a diferentes formas de acesso a esses mesmos bens e serviços. Trata-se de um mecanismo/processo social produtor de sentido

\footnotetext{
3 No que se refere à Psicologia Social, área da primeira autora desse artigo, podemos dizer que ela tem tido participação nesse campo de estudo, de diferentes modos, embora, como lembrou Miller (2007), o domínio exercido por ela até por volta dos anos 1960 declinou consideravelmente. Um dos modos de participação da Psicologia refere-se à aplicabilidade de uma expertise psicológica na área da publicidade e propaganda com o intuito de reificar o consumo como um valor econômico, ou seja, como se posiciona em direção à reflexão sobre como os corpos de conhecimento teórico produzido pela psicologia pode contribuir para fazer operar uma economia de consumo. Há um reforço, de certo modo, de um materialismo.
} 


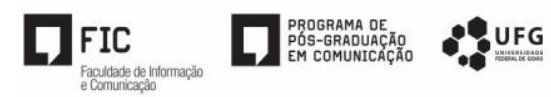

e de identidades, independentemente da aquisição de um bem; uma estratégia utilizada no cotidiano pelos mais diferentes grupos sociais para definir diversas situações em termos de direitos, estilos de vida e identidades (BARBOSA; CAMPBELL, 2006).

O consumo não é uma novidade da modernidade; quando se observa os padrões de comportamento e pensamento da humanidade ao longo da história pode-se ver que ele sempre existiu. A começar pelo consumo de comida, uma necessidade para a sobrevivência de nossa espécie. Entretanto, até mesmo esse consumo se transformou. A comida não tem mais a mesma forma (hoje nos alimentamos com produtos processados industrialmente e que carecem de durabilidade), não tem mais o mesmo conteúdo (à comida são adicionados novos elementos químicos), não tem mais a mesma intensidade (as quantidades de ingestão de alimento aumentaram ou diminuíram para um grande número de pessoas) e sua finalidade mudou (não se come mais apenas para garantir a sobrevivência da espécie).

Enquanto as abordagens anti-materiais parecem se fundar sobre um peculiar preconceito antimaterial, considera-se importante, sob uma perspectiva material, reconhecer "o quanto seu crescimento poderia também ser visto como sinônimo da abolição da pobreza ou do desejo por desenvolvimento" (MILLER, 2007, p.34). Certamente, novos ângulos são necessários "para que se possa examinar e compreender - quiçá transformar - as culturas do consumo. Considerando a situação estratégica do Brasil nos blocos emergentes econômicos, políticos e culturais no contexto da globalização em curso, essa discussão se torna tão necessária quanto urgente" (CASTRO, 2014, p.70).

A perspectiva material adota uma postura diferenciada (em relação às perspectivas anti-materiais) frente ao entendimento do consumo, orientando suas análises pelos estudos da cultura material. Essa abordagem sustenta-se sobre o pressuposto de que nossa cultura banaliza o objeto e seu papel na sociedade, esquecendo seu lugar e função, ou, então, coloca os objetos apenas como fonte ou expressão de alienação (ROCHE, 2000). Desse modo, os estudos da cultura material "trabalham através da especificidade de objetos materiais para, em última instância, criar uma compreensão mais profunda da especificidade de uma humanidade inseparável de sua materialidade" (MILLER, 2007, p.47).

Os estudos da cultura material têm se renovado e adquirido novas sensibilidades, recebendo a nomeação de modern material culture studies (estudos modernos da cultura material). Por esses estudos, salienta Vannine (2009), se tenta redescobrir o significado dos objetos, especialmente em termos de seu papel cultural. Estudar a cultura material significa 
estudar as bases tecnológicas da cultura, e estudar a tecnologia, é estudar o caráter material da vida cotidiana e de seus processos de objetivação, Isto é , assinalar a importância de tratar a vida cotidiana como uma forma ativa de negociação que envolve as cores, as texturas, os gostos, as fragrâncias , os sons, a temperatura, o movimento cinestésico, e o valor simbólico e prático do material que compõe a vida. (VANNINE, 2009, p.3) [tradução das autoras]

Embora seja difícil encontrar um conceito de cultura material bem preciso, pode-se partir da ideia de que a "materialidade e a cultura material se referem a uma visão da experiência humana na qual a subjetividade é profundamente material"4 (GEISMAR, 2011, p.211). Aqui se volta o interesse aos objetos per se, ou seja no que sua materialidade expressa, isto é, é a materialidade de um objeto que condiciona os sentidos que ele pode liberar (ROCHE, 2000). Os objetos são importantes justamente por que não os "enxergamos" de fato. Quanto menos estamos conscientes deles, mais força eles têm para determinar nossas expectativas (GEISMAR, 2011) e, quiçá, engendrar afetos.

Diferentemente da perspectiva anti-material, o objeto é tomado como manancial de criação e engenhosidade. Assim,

Se admitimos que o mundo exterior dos objetos não é o local da nossa total alienação, e sim um meio de um processo criativo, e que a relação do indivíduo com o social passa pela objetificação, a história do consumo permite compreender melhor a continuidade do material e do simbólico, o esforço de inteligência e trabalho cristalizado que se conserva no menor objeto, a união entre as representações e a realidade. (...). Trata-se de compreender os limites do possível, isto é, como nascem as possibilidades de transformação, como os efeitos negativos e positivos se entrelaçam quando as rupturas se produzem. (...). (ROCHE, 2009, p. 19)

Estudos de cultura material trabalham através da especificidade de objetos materiais para criar uma compreensão mais profunda da especificidade de uma humanidade inseparável de sua materialidade. Não se consome apenas para aquisição de bens; apropia-se de bens, muitas vezes, como um modo se transformar criativamente esses bens (MILLER, 2007).

O desenvolvimento de uma abordagem de cultura material é algo que ajuda adesmembrar a especificidade do consumo, e mostrar que a materialidade de cada gênero é em si mesma importante, além dessa materialidade precisar ser contextualizada, já que um objeto não é a mesma coisa para grupos sociais e populações distintas. Isso ocorre por que os objetos podem sofrer extensas transformações ao longo do tempo (MILLER, 2007).

\footnotetext{
$4 \quad$ Tradução livre das autoras: "Materiality and material culture refer to a vision of human experience in which subjectivity is profoundly material" (GEISMAR, 2011, p.211).
}

Comun. \& Inf., Goiânia, GO, v. 20, n. 1, p. 92-114, jan./jun. 2017 
Em consonância com essa perspectiva, encontramos Canclini (2006), que acredita que o estudo do consumo pode nos auxiliar a entender os cidadãos, porque a participação social é, em grande parte, organizada através do consumo. Na linguagem do dia-a-dia, consumir costuma estar associado a gastos inúteis, mas é possível olhar para o consumo como um espaço propício para pensar e um espaço organizador da racionalidade econômica, sóciopolítica e psicológica nas sociedades contemporâneas. Há uma relação visível entre identidade e consumo, pois entende que as identidades se definem através do consumo e podem se tornar instáveis na medida em que cresce a variedade de produtos. Consumir é uma maneira de ser. E ele admite que no consumo se constrói parte da integração e da comunicação dentro de uma sociedade, como um processo em que os desejos se transformam em demandas e em atos que são socialmente regulados por meio dos significados culturais. O desejo de possuir o novo depende da cultura coletiva a que se pertence, pois as pessoas intercambiam objetos para satisfazer necessidades fixadas culturalmente, de modo a integrarem-se e se distinguirem uns dos outros, para realizarem desejos e para pensarem em sua situação no mundo, para controlarem o fluxo errático dos desejos e dar-lhes constância ou segurança em instituições e rituais.

Em outras palavras, o autor enfatiza o valor do consumo e do significado deste na produção de subjetividade via participação social. Ao invés de enfatizar as possíveis negatividades do consumo, prefere encontrar o que o consumo produz, cria com o sujeito e para a sociedade.

Carlos Milani (2008), que estuda políticas públicas e elementos da participação social, nos diz que a participação social cidadã é aquela que configura formas de intervenção individual e coletiva, que supõem redes de interação variadas e complexas determinadas por relações entre pessoas, grupos e instituições com o Estado. Ela deriva de uma concepção de cidadania ativa, a qual, por sua vez, "define os que pertencem (inclusão) e os que não se integram à comunidade política (exclusão); logo, a participação se desenvolve em esferas sempre marcadas também por relações de conflito e pode comportar manipulação" (p.561).

A participação pode ter inúmeros sentidos, dentre eles, pode significar controlar a qualidade dos serviços prestados, a expressão de prioridades acerca de bens públicos futuros, a politização das relações sociais no processo de constituição de espaços públicos para a formulação de políticas públicas locais. Ainda, os "atores políticos, ao decidirem pela participação, podem ter objetivos muito diversos, tais como a autopromoção, a realização da 


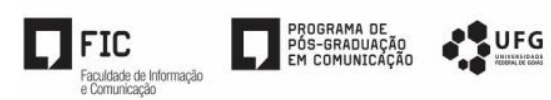

cidadania, a implementação de regras democráticas, o controle do poder burocrático, a negociação ou inclusive a mudança progressiva de cultura política" (MILANI, 2008, p.561).

Nesse sentido, em termos de alargamento das possibilidades de participação cidadã e práticas colaborativas, é inegável pensar na centralidade da internet e, em especial, das mídias sociais baseadas em plataformas de conectividade social (como o Facebook) no cenário contemporâneo, muito embora, como assinala Preece (2001), a sociabilidade online estivesse presente desde os primórdios da internet nos anos noventa do século passado, através das primeiras comunidades virtuais online. Pensando no atual cenário da Web 2.0, autores como Benkler (2006) e Castells (2013) chamam a atenção para o fenômeno da crescente mobilização social via redes sociais online, com a intensificação das possibilidades de participação e colaboração. Para o primeiro, trata-se de pensar na "riqueza das redes" (wealth of networks, no original) para argumentar em favor da organização dos internautas em redes online como espaço profícuo para o exercício da autonomia individual e da liberdade política, possibilitada pelo surgimento de uma esfera pública interconectada que permite a luta por justiça e por igualdade, na forma da mobilização cidadã em "redes de indignação e esperança", como prefere Castells (2013). Já Shirky (2011) enfatiza que a diversidade de formas de engajamento cidadão nas mídias sociais é sustentada por uma cultura da participação online que floresceu a partir do aperfeiçoamento das possibilidades de conexão entre as pessoas comuns, que podem, nesse cenário, ampliar sua voz na demanda pela visibilidade de suas causas: "o custo drasticamente reduzido de se dirigir ao público e o tamanho drasticamente aumentado da população conectada significam que agora podemos fazer coisas de valor duradouro a partir de agregações maciças de pequenas contribuições" (SHIRKY, 2013, p. 144).

Sendo assim, um elemento decisivo nos modos de consumo ligados à participação cidadã é, portanto, a disseminação de acesso à internet via redes sociais digitais (notadamente o Facebook), intensificando "uma lógica de contemporaneidade que é fortemente marcada pela instantaneidade, pela mobilidade e pela virtualidade" (SILVA, 2007, p.12-13). Especialmente nos últimos anos, as plataformas sociais digitais têm contribuído para criar formas de consumo interessantes, com facetas tanto positivas quanto negativas. Hoje, o Facebook, por exemplo, já é considerado "a maior plataforma de mídia" (MITCHEL; DANA, 2013, p.1), com taxa de crescimento acelerado no Brasil, aumentando o número de usuários 13 milhões para 30 milhões no Brasil nos últimos nove meses, de acordo com a iCrossing, que compilou os dados de crescimento do Facebook de 2006 a 2008 (LYONS, 2012). Os

Comun. \& Inf., Goiânia, GO, v. 20, n. 1, p. 92-114, jan./jun. 2017 
dados mais recentes, divulgados pelo próprio Facebook no final de 2016, indicam que a plataforma está a caminho de atingir dois bilhões de usuários (ESTADÃO, 2017) $)^{5}$. No Brasil, já são 102 milhões os brasileiros conectados ao Facebook (o que equivale à metade da população do país), sendo que 93 milhões acessam o Facebook de dispositivos móveis ${ }^{6}$.

Via Facebook, como é popularmente conhecido, pode-se, por exemplo, denegrir a imagem de uma pessoa, invadir sua privacidade, banalizar a política, mas também pode-se reencontrar ex-colegas, cruzar oceanos, descobrir fotos suas que você nem lembrava (ou sabia) que tinha tirado, construir novos relacionamentos amorosos e movimentar politicamente grupos sociais. Possibilidades infinitas se abrem positivamente para o cultivo e invenção de novos encontros humanos e modos diferenciados de participação social, a tal ponto que uma das questões "que se impõe é o papel desempenhado por esse tipo de consumo como elemento de vinculação" (CASTRO, 2014, p.64). Nesse sentido, também é possível compreender as mídias sociais como produtoras de "capital social" que tensionam as noções de pertencimento e laço social, ainda que "uma série de questões metodológicas e conceituais não resolvidas relacionadas ao conceito e à medida do capital social" (TZANAKIS, 2013, 13, tradução das autoras $)^{7}$.

A concepção do sociólogo Mario Diani (1997), baseada em Bourdieu (1986), PUTNAM (1993) e COLEMAN (1988), pode iluminar a reflexão sobre os impactos sociais da apropriação da internet. Para o autor, capital social são laços que, apesar de não implicarem necessariamente uma identidade coletiva, "são baseados em sentimentos de confiança mútua e reconhecimento mútuo entre os atores envolvidos. Quanto mais ampla for a gama de laços de capital social que emergem de um período de mobilização consistente, maior será o impacto de um movimento social" (DIANI, p.130, 1997, tradução das autoras). Uma mídia social, como o Facebook, se mostra como um território onde as pessoas podem se reconhecer, se sentir pertencendo a algo, construir laços mesmo sem terem uma identidade coletiva definida e, a partir desse manancial constituir-se como potência de capital social que influencia na participação social.

Com certeza pode-se afirmar que o consumo nas sociedades em rede mudou de forma, conteúdo, intensidade e finalidade, impactando sobremaneira as relações sociais, os modos de

\footnotetext{
5 Informação extraída de http://link.estadao.com.br/noticias/empresas,facebook-esta-perto-de-alcancar-2bilhoes-de-usuarios-no-mundo,70001649767 Acesso em: 26 jun 2017.

6 Informação extraída de https://www.facebook.com/business/news/102-milhes-de-brasileiroscompartilham-seus-momentos-no-facebook-todos-os-meses Acesso em: 26 jun 2017.

7 Tradução livre das autoras: "a number of unresolved methodological and conceptual issues related to the concept and measurement of social capital" (TZANAKIS, 2013, 13, tradução das autoras).
}

Comun. \& Inf., Goiânia, GO, v. 20, n. 1, p. 92-114, jan./jun. 2017 
pertencimento, as construções dos laços sociais, engendrando práticas culturais e sociais diversas. Daí a necessidade de ampliar esforços interdisciplinares, articular teorias e contextos diferenciados (online e offline) para buscar a aproximação, com mais intensidade, de certo objeto social, no caso dessa escrita, as práticas de consumo relacionadas às redes sociais digitais.

Buscando adensar as reflexões no campo de Estudos da Cultura Material, esse artigo reflete parte da caminhada do projeto de pós-doutorado da primeira autora deste artigo, psicóloga social, orientada pela segunda autora, comunicadora. O projeto teve como objetivo geral promover a realização de estudos de alto nível no que se refere às relações de gênero, às práticas socioculturais cotidianas e às representações sociais associadas ao consumo das Tecnologias da Informação e Comunicação (TICs), especialmente de telefones celulares e sites de redes sociais como o Facebook. Teve como meta geral o fortalecimento da proponente em duas instâncias: estudos da cibercultura (instância teórica) e estudos etnográficos (instância metodológica).

O Projeto inseriu-se no Programa de Pós-Graduação em Comunicação, da Universidade Federal de Santa Maria, na Linha de Pesquisa "Mídia e Estratégias Comunicacionais. A proponente inseriu-se nas atividades em uma comunidade localizada no Bairro Villa Nova ${ }^{8}$, de uma cidade do interior do Rio Grande do Sul, desenvolvidas a partir do projeto de nível superior (projeto guarda-chuva), cujo objetivo, em síntese, é pensar no papel das Tecnologias da Informação e Comunicação (TICs) no enfrentamento de questões sociais e investigar as práticas cotidianas, as representações e as expectativas associadas ao consumo da internet. Assim, o problema de pesquisa proposto no projeto busca responder à seguinte questão: quais são as práticas socioculturais e as estratégias de apropriação da internet (especialmente dos sites de redes sociais) e dos telefones celulares acionadas pelos habitantes das periferias urbanas de duas cidades localizadas em estados diferentes e em qual medida tais tecnologias de comunicação e informação propiciam formas de inclusão e participação cidadã?

Acompanhando as atividades do projeto da orientadora e auxiliando na consecução dos objetivos do projeto da mesma, a pós-doutoranda buscou, a partir de um delineamento etnográfico, entender os impactos sociais da apropriação da internet por parte de líderes comunitários em uma cidade localizada na região centro-oeste do Rio Grande do Sul, Brasil. A pesquisa foi desenvolvida em uma comunidade localizada em uma cidade no interior do

$8 \quad$ Nome fictício.

Comun. \& Inf., Goiânia, GO, v. 20, n. 1, p. 92-114, jan./jun. 2017 
referido estado. Durante 11 meses, as pesquisadoras seguiram o perfil na rede social Facebook de um líder comunitário e sua esposa. Especificamente, intencionou-se analisar as postagens relacionadas a questões comunitárias com o intento de identificar elementos relacionados à participação cidadã.

Entende-se aqui por participação cidadã "uma prática que reúne e integra pessoas conscientes de que, além de um projeto pessoal de vida, é necessário igualmente exercer um papel efetivo na construção coletiva da sociedade, de modo que se garantam os direitos fundamentais de cidadania e uma vida digna para todos" (NORI, 2010, p.14). Nesse sentido, pretendeu-se analisar temas relacionados a assuntos comunitários tal como debatidos no Facebook. Assim como Silva (2007, p. 8) utilizou um site de relacionamento (Orkut®) como um dos campos de sua pesquisa etnográfica envolvendo o uso de celulares, também estamos recorrendo ao Facebook ${ }^{\circledR}$ como "forma privilegiada de acesso às novas práticas sociais e culturais e aos imaginários que circulam no Brasil". Nesse sentido, Miller et al (2016) chamam a atenção para a importância de estudos que se preocupem com as apropriações locais de tecnologias de comunicação e informação globais como o Facebook. Na perspectiva dos autores, trata-se de pensar as práticas de consumo de tais tecnologias como profundamente atravessadas pelas culturas locais - a mirada analítica preocupa-se, assim, em considerar que as mídias sociais podem ser apropriadas de formas bastante diferentes em distintas partes do mundo.

\section{METODOLOGIA}

A pesquisa aqui apresentada é uma ramificação do Projeto "Práticas socioculturais e estratégias de apropriação da Internet e dos telefones celulares para a inclusão social e a participação cidadã em periferias urbanas do sul do Brasil"'. A população-alvo do projeto é uma comunidade localizada no Bairro Villa Nova ${ }^{10}$, em uma cidade do interior do Rio Grande do Sul. O ponto de referência para acessar a comunidade é uma associação de bairro, cujo líder e sua esposa são foco neste artigo.

Trata-se de uma pesquisa de caráter etnográfico (QUEIROZ et al., 2007; BEAUD; WEBER, 2007) que adota como campo de estudo o território internet. A internet, seguindo a lógica de Miller (2000; 2013), não será vista como uma nova realidade, ou uma realidade virtual, mas como uma nova forma de mediação, que modifica a tecnologia e seus contextos.

9 Este projeto foi contemplado no Edital MCTI /CNPq /MEC/CAPES No 18/2012 - Ciências Humanas, Sociais e Sociais Aplicadas.

$10 \quad$ Nome fictício.

Comun. \& Inf., Goiânia, GO, v. 20, n. 1, p. 92-114, jan./jun. 2017 
Ela é tomada como um espaço importante às pessoas como parte do cotidiano e não à parte dele. O estudo de Don Slater e Daniel Miller (2000), materializado no livro The Internet - An Ethnographic Approach, realizado em cibercafés de Trinidad-Tobago serve como referência para nossa pesquisa. Para os autores, o problema principal é o do estabelecimento de uma etnografia que assuma como foco a incorporação da internet à cultura material de uma dada coletividade. Os autores afirmam que é preciso superar dualidades (separação de offline e online) relacionando contexto e fenômeno de forma recíproca. É preciso prestar atenção às formas em que o objeto e o contexto precisam ser definidos, em relação um ao outro, para projetos etnográficos específicos. Às vezes, o uso da internet parece constituir virtualidades, às vezes não.

Miller, no artigo "Etnografia on e off-line: cibercafés em Trinidad", publicado na revista Horizontes Antropológicos em 2004, tenta clarear o que exatamente se pode dizer com os contextos e as molduras da pesquisa etnográfica que trabalham com contextos da internet. Argumenta que, na antropologia, os critérios primários da etnografia incluem a observação participante e o tempo passado na comunidade ou no espaço social estudado. O tempo de observação participante de um ano é geralmente especificado como um período mínimo para o encontro na pesquisa de campo. Esse tempo estendido despendido de participação possibilita que os objetos e sujeitos de pesquisa possam ser vistos no âmbito de molduras ou contextos mais amplos, de modo que se consiga um conhecimento mais "holístico" do fenômeno. Em sua pesquisa em Trinidad ponderou que

a qualificação para ser considerada como uma etnografia não foi se se pesquisou especificamente contextos off-line, mas se se partiu do compromisso maior em relacionar o fenômeno a contextos mais amplos (independentemente de como foram definidos) ou se, ao invés, se começou de noções como "virtualidade" ou "ciberespaço", que envolvem uma pressuposição metodológica em que o cenário poderia ser tratado como sui generis, autocontido e autônomo (MILLER, 2004, p. 45).

Para o autor, a etnografia exige que não consideremos a internet como um objeto único com propriedades inerentes ou como um cenário autocontido (ignorando os contextos offline). Na etnografia, o mundo online e o mundo offline são inter-relacionais, do mesmo modo que sujeito e objeto jamais estão separados um do outro. Na mesma linha de argumentação de Miller e Slater (2000) e escrevendo na mesma época, Preece (2001) já alertava, em relação à pesquisa de fatores como sociabilidade e usabilidade online em comunidades virtuais, que o uso de análises baseadas em etnografia constitui uma forma relevante de atingir maior profundidade nos estudos. 
Desse modo, no processo etnográfico, recorremos ao diário de campo, quando se registrou tanto o que se observou na comunidade Villa Nova quanto no ambiente da internet. Pensamentos, sentimentos, afetos, tensões, interações, redes estabelecidas e ações realizadas foram incluídos desde o início, marcando a necessidade de uma análise de implicação.

A análise de implicação inclui uma análise do sistema de lugares (inclusive e especialmente do pesquisador), o assinalamento do lugar que ocupa nos jogos/redes de poder, que busca ocupar e do que lhe é designado ocupar com os riscos que isto implica (AGUIAR; ROCHA, 2007). Implica a abertura para criar zonas que possam favorecer o coletivo a aflorar, dirigindo à invenção e a outros modos de expressão, sendo uma coprodução/transformação micropolítica, tanto de quem se propõe a conhecer, quanto de quem é conhecido (PAULON; ROMAGNOLI, 2010).

$\mathrm{O}$ que se pretendeu neste processo de inserção na comunidade não foi fazer interpretações como revelações de alguma verdade, mas criar sentidos e possíveis movimentos de ruptura nas representações sociais e nos modos de interagir com as TICs. Assim, não há "o que ser revelado, descoberto ou interpretado, mas criado" (ROCHA; AGUIAR, 2003, p. 72). O pesquisador não interpreta, mas inventa novas possibilidades e rupturas de sentido (AGUIAR; ROCHA, 2007). Ele pensa problematicamente, coloca questões às perguntas em lugar de respostas. "como processo de formação, acionador de movimentos de estranhamento, de desacomodação, de 'perguntação' e de implicação, potência para um coletivo diferir de si mesmo e de dobrar novas práticas" (CECCIM; FERLA, 2009, p. 43).

As análises têm cunho descritivo, consistindo em um processo de tomar o fluxo de dados e decompô-lo em suas partes constitutivas, quando se busca, inicialmente, fazer uma leitura panorâmica, esclarecer o uso de certas categorias, identificar os padrões e as (ir) regularidades (AGROSINO, 2009). As reflexões sobre as informações observadas e o processo de pesquisa em si se apoiaram especialmente em autores que fazem leituras com base nos Estudos da Cultura Material (e.g., CANCLINI, 2006; MILLER, 2004, 2007; CASTRO, 2014).

As pesquisadoras se inseriram no bairro Villa Nova onde reside Seu X e participaram de diversos espaços acessados em seu cotidiano, tais como residência, escola da comunidade, associação de bairro, etc., fazendo anotações em diário de campo ${ }^{11}$. Nesse artigo, apresentou-

11 Os relatos apresentados nesse artigo foram extraídos do Diário de Campo da pós-doutoranda. 
se os dados construídos especialmente a partir de nossas observações no perfil do Facebook, o qual acompanhamos durante 11 meses (junho de 2014 a abril de 2015).

Fazer esse recorte "espacial online" (Facebook) não significa que a pressuposição de Miller (2004) foi desconsiderada pelas pesquisadoras - de que nem a internet é dada como uma tecnologia que é o objeto de estudo, nem o Villa é separado como um contexto social ou cultural. Ao contrário, objetiva-se examinar a internet como um processo cultural do Villa, assim como entender como o Villa pode agora ser, dentre outras coisas, um produto do uso da internet.

Por primeiro, será contado um início da história do casal, de modo a contextualizar de onde vieram e como se inserem na comunidade hoje, considerando o que construímos com nossas conversas informais. Após, será trazido o deambular das pesquisadoras no Facebook de Seu X.

\section{APRESENTANDO OS DADOS: NA LINHA DO TEMPO DE SEU $X$}

Seu X, um senhor beirando seus 60 anos, casado com Dona Y, é liderança em uma das maiores comunidades de uma cidade do interior do Rio Grande do Sul. Juntamente com sua esposa, também liderança comunitária, foi um dos primeiros moradores do local, uma fazenda que foi sendo invadida aos poucos por pessoas de diferentes regiões circunvizinhas. Aliás, Dona Y foi uma das primeiras "invasoras" daquelas terras latifundiárias no início dos anos 90. Os dois moravam em uma cidade satélite, quando Seu $\mathrm{X}$ adoeceu e acabou sendo internado no hospital da cidade central. "Entortou tudo, as mãos e os pés (representa com seu próprio corpo). Ninguém sabia o que era. Ficou assim por uns 8 meses" $(\mathrm{Y})^{12}$. Como tinha que pegar ônibus todos os dias e deixar seus filhos com uma vizinha que "bebia e ficava muito braba. Imagina o que eu sentia, como ficava... deixar minhas crianças ali, mas não tinha outro jeito. Daí, comentei com um primo meu que queria comprar uma casa perto do hospital e ele disse que era 'só chegar', que não havia casas, era só campo, que estavam construindo alguns barracos por ali, mas não tava pronto" (Y).

Chegaram à noite. Seu primo a deixou ali e se foi. Dona Y escolheu onde queria morar - no final do que hoje seria avenida principal do bairro. "Era umas 9 horas da noite me fui caminhando sozinha até a parada. Era tudo escuro. Nem sabia pra que lado" (Y). Mas ela estava determinada a voltar à sua cidade, buscar suas coisas e ir morar ali. Logo encontrou a parada de ônibus e foi para sua casa. Chegando lá, contou aos familiares sobre sua decisão e a

$12 \quad \mathrm{Y}=$ relato de Dona $\mathrm{Y}$.

Comun. \& Inf., Goiânia, GO, v. 20, n. 1, p. 92-114, jan./jun. 2017 
chamaram-na de louca. Ofereceu ao pai de seu primo suas seis vacas e um cavalo para vender. "Ele comprou e disse que estava fazendo aquilo porque sabia que meu pai faria o mesmo pelos filhos dele e até ia pagar mais do que pedia, porque sabia que eu precisava" (Y).

Conta com orgulho e olhando diretamente nos olhos da pesquisadora (Adriane) que desmontou sua casa sozinha, tirou telha por telha e "alcançava a telha para meu pequeno de dois anos e ele ia ajudando" (Y). Quando chegou ao pedaço de terra escolhido, arrumou as crianças dentro de uma caixa de papelão e um acolchoado. Com dois pedaços de pau e uma lona fez uma casa. "A guria tava roxa de tanto frio que fazia. Aí, eu disse pro guri cuidar dela que eu ia buscar alguma coisa pra comer. Fui lá na faixa, no único mercado que tinha [dizo nome do mercado] e comprei pão e salame. Não é que minha família não tinha condições, mas eu precisava me mudar. Era o jeito" (Y).

Dona $\mathrm{Y}$ ia ver seu marido todos os dias no hospital e levava as crianças junto. Com um tom de voz que soava culpa, comenta que, como não era permitida a entrada de crianças, deixava os dois na pracinha e dizia para o mais velho cuidar da irmã. Repetiu essa história duas vezes e terminou dizendo que "era o que dava pra fazer" (Y). Em seguida, lembra que tentaram roubar a menina duas vezes.

As conversas com Dona Y eram entrecortadas por alguma pessoa que chegava à sua casa com um balde de plástico ou uma panela de alumínio para buscar sopa, que começava a ser servida gratuitamente desde as seis horas da manhã. Ela se levantava e ia servir, sempre sorridente e com alguma conversa a fazer. Enquanto servia, outras mulheres chegavam, quase sempre acompanhas de filhos.

A casa de Seu X e de Dona Y é muito simples, com as paredes de alvenaria, sem reboco, mas tem dois andares. As pesquisadoras só tiveram acesso à cozinha, à sala e ao banheiro. Também conheceram o pátio dos fundos, onde Dona X cria alguns porcos. Com a porta sempre aberta, o primeiro cômodo é uma sala de recepção, com uma mesa ao canto onde são colocadas as roupas que recebem para a doação, usualmente. Essa mesma mesa estreita e comprida abriga o bolo quando é organizada alguma comemoração. As pessoas que vêm buscar a sopa aproveitam para escolher roupas, sempre escolhendo e mencionando, em conversa informal, para quem levarão a roupa. As roupas estão postas sobre a mesa de modo empilhado e não estão dobradas. Costumam sair com mais de uma sacola cheia de roupas.

A casa de Seu X e de Dona Y é referência para a Associação Comunitária que eles criaram e gerenciam, apesar de hoje eles contarem com uma sede própria, ainda que em condições estruturais muito precárias. Dona Y conta que a ideia da associação começou com o 
sopão. Certo dia bateu à porta da casa deles uma senhora pedindo comida. Dona Y deu o que tinha e, com a conversa, ficou sabendo que a mulher tinha dez filhos. Dona Y, comovida, falou que mais tarde passaria na casa dela para levar mais comida. Quando chegou lá, se deparou com o estado "deplorável" [ $[\mathrm{sic}]^{13}$ das crianças, especialmente uma menina, que por desnutrição já não conseguia mais andar. Foi a partir desta experiência que Dona Y teve a ideia de começar a fazer sopa na sua casa e servir àqueles que necessitassem.

Nos cômodos do andar térreo não se vê televisão, nem computador, apenas um rádio pequeno na cozinha e no alto de um dos armários uma estátua de Nossa Senhora Aparecida, mas há um computador que fica no andar de cima, onde as pesquisadoras não tiveram acesso. Seu X utiliza o computador para entrar no Facebook com mais frequência que Dona Y, que quase não acessa e declara: "não tenho tempo pra isso" (Y).

$\mathrm{O}$ perfil no Facebook de Seu $\mathrm{X}$ foi seguido durante 11 meses desde que as pesquisadoras se tornaram amigas dele no Facebook. De modo exploratório, elas acompanhavam o que era postado, tentando observar como essa tecnologia servia para a inclusão de Seu X em diferentes contextos e como ela poderia contar sobre a participação cidadã na comunidade desse líder e da liderança de Dona Y.

A imagem de capa de Seu X é uma foto de seu neto, vestindo um adorno de seu time de futebol. Esse neto nasceu pouco antes de iniciarmos a etnografia. Ele mora na casa de Seu $\mathrm{X}$ e de Dona Y, juntamente com a mãe (filha do casal). Seu X tem 351 amigos no Facebook. Já curtiu 19 páginas. Uma (1) página de cada modalidade: Advocacia (serviços de um advogado), instituição religiosa (Espiritismo), figura pública religiosa (padre católico), mídia/publicidade (MSN para Brasil), organização sem fins lucrativos (Serviço público gratuito de abaixo-assinados), organização política (seção sindical) e organização comunitária (liderada por Seu X). Duas páginas de cada modalidade: página de aplicativo (jogo e Facebook para telefone), roupas/calçados/acessórios, e políticos (ambos do Partido da Social Democracia Brasileira - PSDB). Três (3) páginas de cada modalidade: comunidade e time de futebol.

Na modalidade comunidade, uma trata de manter firme a cultura, a tradição e os valores gaúchos, outra se relaciona com partilhar receitas culinárias e a terceira é uma página administrada por uma revista e por colaboradores para cobertura das manifestações na cidade onde mora Seu X.

13 Segundo informações colhidas (fala literal da informante).

Comun. \& Inf., Goiânia, GO, v. 20, n. 1, p. 92-114, jan./jun. 2017 
Com relação aos eventos que Seu X marcou participação, dois foram promovidos por políticos da cidade em que mora e um promovido pela associação que Seu X lidera. Os políticos (candidatos a deputado estadual) são do partido DEM (Democratas) e PSDB (Partido da Social Democracia Brasileira), partidos coligados na eleição de 2014.

O trânsito diário no perfil do Facebook de Seu X, a leitura e releitura das postagens possibilitou que se construísse um quadro de análise contendo os seguintes tópicos: mês da postagem, autor da postagem, tema, tipo de posicionamento, imagem, autoria da imagem, compartilhamento de mensagem, texto autoral, número de curtidas, "sexo" da curtida. Quando postagens repetidas foram encontradas, optou-se por incluir na amostra aquela postagem que tivesse o maior número de curtidas.

Nesse período, foram construídas 57 postagens, sendo que os meses com maior número de postagem foram outubro (13), agosto e fevereiro (7), mas pode-se dizer que em média, Seu X posta uma vez por semana, com exceção dos meses novembro e dezembro, quando ele postou uma vez em cada. Do total de postagens, $51(87,9 \%)$ são de Seu X. As demais 7 (12,06 \%) são de autoria de 1 ator governamental, 1 amigo do Facebook e 6 amigas do Facebook.

Em relação aos temas e ao tipo de posicionamento, classificamos as 57 imagens/textos em 8 temas, enquadrados em 5 tipos de posicionamento, conforme o que segue: 8 homenagens a time de futebol (posicionamento esportivo), 2 mensagens religiosas: cristã e cristã/umbanda (posicionamento religioso), 27 mensagens anti-PT: 22 contra Dilma e 5 contra Lula (posicionamento político), 7 ações da Associação liderada por Seu X (posicionamento comunitário), 2 postagens sobre racismo: 1 contra redução da maioridade penal e 1 contra o racismo entre brancos e negros (posicionamento político), 2 mensagens sobre corrupção em geral (posicionamento político), 8 conteúdos relacionados à família (posicionamento privado) e 1 postagem favorável ao Partido da Social Democracia Brasileira (posicionamento político).

Quadro 1 - Temas e Modos de Posicionamento de Seu X no Facebook

\begin{tabular}{|c|c|c|c|}
\hline $\begin{array}{ll}\text { Modos } & \text { de } \\
\text { Posicionamento } & \end{array}$ & Tema & Total de Postagens & Percentual \\
\hline Esportivo & $\begin{array}{l}\text { Homenagens a time de } \\
\text { futebol }\end{array}$ & 8 & 14,0 \\
\hline Religioso & Mensagens religiosas & 2 & 3,6 \\
\hline \multirow{3}{*}{ Político } & Anti-PT & 27 & 47,3 \\
\hline & Racismo & 2 & 3,6 \\
\hline & Corrupção em geral & 2 & 3,6 \\
\hline
\end{tabular}




\begin{tabular}{|l|l|l|l|}
\hline & $\begin{array}{l}\text { Favorável ao Partido da } \\
\text { Social Democracia } \\
\text { Brasileira }\end{array}$ & 1,7 \\
\hline Comunitário & $\begin{array}{l}\text { Ações da Associação } \\
\text { liderada por Seu X }\end{array}$ & 7 & 12,2 \\
\hline Privado & Família & 8 & 14,0 \\
\hline TOTAL & ------ & 57 & 100,0 \\
\hline
\end{tabular}

Fonte: Elaborada pelas autoras.

Catalogamos o número de curtida de acordo com o tipo de posicionamento. Foram 5 curtidas que se relacionam a postagens com posicionamento esportivo, 23 a posicionamento religioso, 94 a posicionamento político, 100 a posicionamento comunitário e 112 a posicionamento privado ${ }^{14}$.

$\mathrm{Na}$ autoria das imagens, isto é, de onde procede a foto, cartaz, vídeo, charge etc., encontramos a maioria proveniente de algum amigo(a) do Facebook (16 do sexo masculino e 11 do sexo feminino). Em segundo lugar, as imagens são originárias de páginas com viés político, somando um total de 12. Revoltados ON LINE conta com 6 aparições, Fora PT com 2, e o restante com 1 aparição cada (Partido Anti-PT, É mentira do PT, Aécio Neves, Ranking Políticos). Em terceiro, são as páginas esportivas (Artes Coloradas e Como é bom ser colorado). Em quarto lugar páginas relacionadas à religião ou espiritualidade, empatada com imagens provenientes da própria Associação Comunitária liderada por Seu X.

De todas as mensagens postadas, observamos que apenas 6 delas foram compartilhadas. Desse total, 2 foram replicadas pelo próprio Seu X, 1 pela Associação liderada por ele e 3 por amigos(as) do Facebook. Cada compartilhamento, contou com um texto escrito por parte do compartilhador.

\section{DISCUSSÃO E ANÁLISE DOS DADOS}

De início, pode-se afirmar que as observações conduzem a reconhecer que o Facebook consiste num território que possibilita a participação cidadã, conforme definição trazida na introdução desse artigo (e.g., NORI, 2010), já que ali se instaura uma prática que reúne e integra Seu X a diversas pessoas de modo consciente, por escolha pessoal. Essa participação ocorre via dois níveis: o privado, quando o Facebook serve como palco de afeto familiar, e o público, quando o Facebook serve de palco para lançar posicionamentos políticos. Em seu

14 Não conseguimos identificar o "sexo" da curtida, pois algumas postagens foram excluídas, quando fomos fazer esse levantamento. 
projeto pessoal de vida, Seu X vai exercendo um papel efetivo na construção coletiva da sociedade, com base em suas ideologias, buscando direitos fundamentais de cidadania e uma vida digna para aqueles que vivem no seu contexto.

No nível privado, pode-se interpretar o consumo desta tecnologia como produzindo elementos positivos a partir do afeto que é lançado em suas postagens. Seu X consome a tecnologia construindo redes afetivas, o que se confirma com as curtidas de amigos e parentes no que se refere tanto ao privado como àquilo que da ordem pública, mostrando que "as interações entre pares configuram o canal no qual se tece certo sentido de comunidade" (CASTRO, 2014, p.68), de pertencimento e reconhecimento.

Os temas a respeito de assuntos comunitários, tal como debatidos no Facebook, foram pontuais e locais, em certo sentido, pois foram apenas duas postagens nesse âmbito; uma tratava das condições precárias de uma via pública de automóveis e a outra buscava arrecadar verbas para a construção de uma nova sede para a Associação.

Ao somarmos o posicionamento privado, com o esportivo e o religioso, é possível encontrar 31, 6\% contra 56,2 de posicionamento político. Ainda, se unirmos o posicionamento político com o comunitário, chegamos a 68,4\%. Quer dizer, há mais postagens no campo público que no privado. O que se produz, num primeiro olhar, parece ser de pouco valor. No entanto, sob a perspectiva material, podemos interpretar as postagens de Seu X como uma mostra de pertença ao seu bairro. É ali que ele habita, é reconhecido e se reconhece. Assim, via Facebook também se constrói capital social, isto é, "laços sociais baseados em solidariedades coletivas" (DIANI, 1997, p.134).

Seria simplista deduzir que suas postagens são apenas de interesse coletivo, pois, em sua tática de reivindicar via Facebook, é possível, num olhar mais atento, observar que as postagens respondem também seus anseios privados. Se o bairro Villa Nova aparece "como o lugar onde se manifesta um 'engajamento' social ou, noutros termos: uma arte de conviver com parceiros (vizinhos, comerciantes) que estão ligados a você pelo fato concreto, mas essencial, da proximidade e da repetição" (MAYOL, 2013, p. 39), denunciar que as ruas de seu bairro precisam de conserto, é usar o objeto "rua" como um marcador de participação social e uma sinalização de que este espaço público também dá continuidade ao espaço privado. Nesse sentido, o Facebook é um instrumento tático para se definir o bairro "como uma organização coletiva de trajetórias individuais" (MAYOL, 2013, p. 46). Assim, o que Seu X conquista 
quando sabe 'possuir' direito o seu bairro não é contabilizável, nem se pode jogar numa troca necessitante de uma relação de forças: o adquirido trazido pelo costume não é senão a melhoria da 'maneira de fazer', de passear, de fazer compras, pela qual o usuário pode verificar sem cessar a intensidade da sua inserção no ambiente social (MAYOL, 2013, p. 45).

Ao tomar-se a comunidade como algo para além de um espaço geográfico, do espaço de convivência diária, pode-se ver que Seu X se engaja em outros posicionamentos que, no fim das contas, também incidem diretamente sobre seu território, como é o caso de seus posicionamentos políticos.

Se na casa de Seu X ou na Associação não encontramos sinais diretos de sua ideologia partidária (conforme observações etnográficas na comunidade), no Facebook alcançamos mais visivelmente esse aspecto. Por meio de imagens, em sua maioria caricaturas da então presidenta da República Dilma Rouseff e do ex-presidente Luís Inácio Lula da Silva, Seu X se posiciona contra um partido político. Na maior parte, recorrendo a imagens postadas, esses atores são associados, à corrupção. Deste modo, pode-se entender o Facebook como um território que possibilita a expressão política e, considerando as curtidas ou comentários (ainda que reduzidos), um território que movimenta representações acerca da política.

$\mathrm{O}$ interessante é que, enquanto Seu $\mathrm{X}$ se dedica a colocar postagens com críticas ao partido ao qual ele se mostra opositor (no caso o PT), encontramos apenas uma postagem que favorece um político do partido que Seu X defende. Salienta-se que é um vídeo de campanha eleitoral e que só é possível ver o conteúdo se o internauta clicar sob o mesmo, diferente das postagens com imagem anti-PT, que são vistas "automaticamente" por aquele que visita a página de Seu X. É importante conjecturar que a escassez de postagens com conteúdo/imagem da política defendida por Seu X e uma predominância de postagens contrárias ao PT poderão ter um efeito-rebote: uma publicização maior da ideologia criticada por Seu X. Ou, ainda, podemos pensar que o seu modo de fazer política enfatiza o adversário, as adversidades, porque pouco pode contar com o político que ele defende. Se for considerado que, conforme Diani (1997) salientou, as chances de Seu X influenciar politicamente seu ambiente é dependente da extensão e intensidade das conexões que estabelece com as elites políticas, a ênfase no partido criticado e a pouca conexão com o partido apoiado podem obstaculizar as conquistas das demandas territoriais de Seu X e anuviar a produção de capital social.

Pode-se afirmar, seguindo nossa lógica argumentativa, que o Facebook também pode servir como forma privilegiada de acesso aos imaginários que circulam no Brasil, denotando 
aí algo que é simbólico e material. As postagens podem ser analisadas de uma maneira particular se for levado em conta a materialidade que envolve as práticas na internet. Cada imagem é por si só um objeto que ao mesmo tempo carrega objetos. Dito de outra maneira, quando Seu X, por exemplo, posta um cartaz com o título "Kit Desgraça”, contendo a imagem de um trabalhador, com cara de insatisfação, segurando diferentes objetos subjetificados (cada objeto tem um possessor: Boné do Felipe Massa, Celular da Tim, Camisa do Palmeiras, Bandeira do PT), ele produz uma materialidade que diz não apenas do seu posicionamento político, mas de seu posicionamento frente a outros contextos (esporte, telecomunicações, política), incluído o contexto privado.

\section{CONCLUSÕES}

Nesse artigo, o objetivo foi apresentar parte dos resultados de uma pesquisa etnográfica, que teve como um de seus objetivos conhecer os impactos sociais da apropriação da internet, especificamente do Facebook, como uma ferramenta de participação cidadã do líder comunitário - Seu X - e de sua companheira, também líder - Dona Y. O que construímos no processo diz da singularidade desse casal e da Associação construída por ambos, numa localidade específica e num recorte temporal. Todavia, a construção das análises pode iluminar reflexões sobre outros contextos.

As observações realizadas cotidianamente no perfil do Facebook de Seu X podem levar ao reconhecimento deste como um território que possibilita a participação cidadã, ficando comprovado o que Miller (2007) defendeu sobre a cultura material poder ser olhada pelo viés do desejo por desenvolvimento. Por outro lado, foi salientado que os temas a respeito de assuntos comunitários foram pontuais e locais, em sua maioria, denotando o forte vínculo entre o espaço público e a arena privada.

Se o bairro é o lugar de engajamento primeiro; se é nele que o cidadão deposita seus desejos, constrói seu sentimento de pertença e reconhecimento social, nada mais justo que construir políticas públicas que possam valorizar a aquilo que é reivindicado para o coletivo no espaço público. É necessário intensificar investimentos nas localidades, no microssocial, de tal modo que se potencialize a participação cidadã. Talvez desse modo, se produzam efeitos mais duradouros e benéficos.

Ficou anunciado que neste território digital é possível a expressão de ideologias políticas e a movimentação de representações acerca da política. Nas conversas com Seu X e Dona Y o posicionamento ideológico deles também é evidente, corroborando a noção de que 
não existe um espaço virtual e outro "real"; ambos constroem a realidade. Não há uma nova realidade, mas apenas novas formas de mediação, que modificam a tecnologia e seus contextos, como salientamos na introdução.

O Facebook produz uma materialidade que diz respeito especialmente ao posicionamento político, ao posicionamento frente a esporte e à religião, e sem grandes destaques, ao posicionamento privado (família, relações amorosas, etc.). Certamente, é preciso levar em conta que Seu X é um líder comunitário, sempre interessado e preocupado em atender demandas de sua comunidade. Aí se encontra a pertinência de não dicotomizar espaço público do espaço privado; eles se interconectam à medida que um se inscreve no outro a partir das possibilidades de convivência no cotidiano de cada pessoa.

A partir dos resultados, se pode dar continuidade às pesquisas no território das mídias sociais. A primeira continuidade refere-se ao conceito de política e sua relação com a participação cidadã. No que consiste a arte de fazer política nos contextos de sociedade em rede? Quais caminhos poderiam intensificar o uso da rede como promotora da participação cidadã? A segunda dirige-se a posição e função das mulheres nas redes sociais no que tange à participação cidadã: de que modo elas utilizam as mídias sociais para promover (sua) participação social? Há diferenças de gênero em relação ao uso? A terceira consiste em identificar os movimentos colaborativos entre os seguidores dos líderes da comunidade, de modo a acessar como o capital social influência essas colaborações no que se refere às mudanças políticas: quem são os seguidores dos líderes comunitários? Vivem na mesma comunidade? Como se conectam? Que ações conjuntas eles produzem? Que novos laços sociais e novas identidades são geradas a partir de uma mídia social?

Fica, então, a sugestão para novas pesquisas no campo dos Estudos da Cultura Material, que é aprofundar os estudos sobre as relações entre política, uso de redes sociais como território de participação cidadã, relações de gênero e relação entre capital social e colaboração na rede.

\section{REFERÊNCIAS}

AGROSINO, M. Etnografia e observação participante. Porto Alegre: Artmed, 2009. (Coleção Pesquisa Qualitativa)

AGUIAR, K. F. de; ROCHA, M. L. da. Micropolítica e o Exercício da Pesquisa-intervenção: Referenciais e Dispositivos em Análise. Revista Psicologia: ciência e profissão, v.27, n. 4, p.648-663, 2007. Disponível em: 〈http://www.scielo.br/pdf/pcp/v27n4/v27n4a07.pdf〉. Acesso em: 30 jun. 2017.

Comun. \& Inf., Goiânia, GO, v. 20, n. 1, p. 92-114, jan./jun. 2017 
BARBOSA, L.; CAMPBELL, C. (Org.). Cultura, consumo e identidade. Rio de Janeiro: Ed. FGV, 2006.

BEAUD, S.; WEBER, F. Guia para a pesquisa de campo: Produzir e analisar dados etnográficos. Petrópolis: Vozes, 2007.

BENKLER, Y. The wealth of networks: how social production transforms markets and freedom. New Haven and London: Yale University Press, 2006.

BOURDIEU, P. The forms of capital in J.G. RICHARDSON (ed). Handbook of theory and research for the sociology of education, pp. 241-258. New York: Greenwood Press, 1986.

CANCLINI, N. G. Culturas Híbridas. São Paulo: Editora da Universidade de São Paulo, 2006.

CASTELLS, M. Redes de indignação e esperança: movimentos sociais na era da internet. $1^{\text {a }}$. Ed. Rio de Janeiro: Zahar, 2013.

CASTRO, G. G. S. Comunicação e consumo nas dinâmicas culturais do mundo globalizado. pragMATIZES - Revista Latino Americana de Estudos em Cultura. n. 6, p. 58-71, mar. 2014. Disponível em:

<http://www.pragmatizes.uff.br/revista/index.php/ojs/article/view/55/47>. Acesso em: 30 jun. 2017.

CECCIM, R. B., FERLA, A. A. Educação e Saúde: ensino e cidadania como travessia de fronteiras. Trab. Educ. Saúde, 6(3):443-56, nov./fev. 2009.

COLEMAN, J.S. Social capital and the creation of human capital. American Journal of Sociology, n. 94, p. 95-120, 1988.

DIANI, M. Social movements and social capital: a network perspective on movement outcomes. Mobilization: An International Journal, v. 2, n. 2, p. 129-147, 1997.

GEISMAR, H. "Material Culture Studies" and other Ways to Theorize Objects: A Primer toa Regional Debate. Comparative Studies in Society and History . [S.1.; s.n.], v. 53, n. 1, p. 201- 211, 2011. Disponível em: <http://www.academia.edu/2538482/_Material_Culture_Studies_and_other_Ways_to_Theori ze_Objects_A_Primer_to_a_Regional_Debate?login=adrianeroso@gmail.com\&email_was_ta ken=true>. Acesso em: 30 jun. 2017.

LYONS, Gregory. Facebook to Hit a Billion Users in the Summer. iCrossing, Jan. 11, 2012. Disponível em http://connect.icrossing.co.uk/facebook-hit-billion-users-summer_7709 Acesso em: 30 jun. 2017.

MAYOL, P. O bairro. In: CERTEAU, M.; GIARD, L.; MAYOL, P. A invenção do cotidiano: 2. Morar, cozinhar. Petrópolis: Vozes. 2013. p. 37-45. 
MILANI, Carlos R. S. O princípio da participação social na gestão de políticas públicas locais: uma análise de experiências latino-americanas e européias. RAP - Rio de Janeiro 42(3):551-79, maio/jun. 2008. Disponível em:

<http://www.researchgate.net/profile/Carlos_R_S_Milani/publication/250991234_O_princpio _da_participao_social_na_gesto_de_polticas_pblicas_locais_uma_anlise_de_experincias_lati no-americanas_e_europias/links/5492ca520cf225673b3e0b68.pdf >. Acesso em: 30 jun. 2017.

MILLER, D. Trecos, troços e coisas. Estudos antropológicos sobre a cultura material. Rio de Janeiro : Zahar, 2013.

MILLER, D. Consumo como cultura material. Horiz. antropol., Porto Alegre , v. 13, n. 28, p. 33-63, dez. 2007. Disponível em:

$<$ http://www.scielo.br/scielo.php?script=sci_arttext\&pid=S0104-

$71832007000200003 \& \operatorname{lng}=$ en\&nrm=iso $>$. Acesso em: 30 jun. 2017.

MILLER, D.; SLATER, D. The Internet. An Ethnographic Approach. Oxford, New York: Berg, 2000.

MILLER, Daniel; SLATER, Don. Etnografia on e off-line: cibercafés em Trinidad. Horiz. antropol., Porto Alegre, v. 10, n. 21, p. 41-65, June 2004. Available from $<\mathrm{http}: / / \mathrm{www}$.scielo.br/scielo.php?script=sci_arttext\&pid=S0104$71832004000100003 \& \operatorname{lng}=\mathrm{en} \& n r m=$ iso $>$. Acesso em: 30 jun. 2017.

MILLER, D. et al. How the world changed social media. London: University College London Press, 2016.

MITCHELL, A.; DANA, P. The Role of News on Facebook. Common yet Incidental. Research Report. Pewresearch.org, October, 2013. Disponível em: <http://www.journalism.org/files/2013/10/facebook_news_10-24-2013.pdf>. Acesso em: 30 jun. 2017.

NORI, Célio. O que se entende por Participação Cidadã. In: Escola de Cidadania de Santos, Cartilha da Participação Cidadã, p.13-17. Santos: Diocese de Santos, Fórum da Cidadania de Santos, Universidade Católica de Santos, 2010. Disponível em $<$ http://www.forumdacidadania.org.br/Cartilha\%20da\%20Cidadania\%20$\% 20 \mathrm{P} \% \mathrm{C} 3 \%$ A1ginas\%20Simples.pdf $>$. Acesso em: 30 jun. 2017.

PAULON, S. M.; ROMAGNOLI, R. C. Pesquisa Intevenção e cartografia: Melindres e meandros metodológicos. Estudos e Pesquisa em Psicologia (UERJ). Rio de Janeiro v.10, n.1, p.85-102, $1^{\circ}$ quadrimestre de 2010. Disponível em: :

<http://www.revispsi.uerj.br/v10n1/artigos/pdf/v10n1a07.pdf>. Acesso em: 30 jun. 2017.

PREECE, J. Sociability and usability: Twenty years of chatting online. Behavior and Information Technology Journal, 20, 5, p. 347-356, 2001.

PUTNAM, R. D. The prosperous community. The American Prospect, v. 4, n. 13, p. 35-42, 1993. 
QUEIROZ, D. T. et al. Observação participante na pesquisa qualitativa: conceitos e aplicações na área da saúde. Revista de Enfermagem UERJ, Rio de Janeiro, v. 15, n. 2, p. 276-83, abr./jun. 2007.

ROCHA, M. L. da; AGUIAR, K. F. de. Pesquisa-intervenção e a produção de novas análises. Revista Psicologia: ciência e profissão, v.23, n.4, p.64-73, dez. 2003. Disponível em: $<$ http://pepsic.bvsalud.org/scielo.php?pid=S1414-98932003000400010\&script=sci_arttext $>$. Acesso em: 30 jun. 2017.

ROCHE, D. História das coisas banais: nascimento do consumo séc. XVII XIX. Rio de Janeiro: Rocco, 2000.

SANTOS, Marinês Ribeiro dos. Design e cultura: os artefatos como mediadores de valores e práticas sociais. In: QUELUZ, Marilda Lopes Pinheiro (Org.). Design \& Cultura. Curitiba: Editora Sol, 2005.

SHIRKY C. A cultura da participação: criatividade e generosidade no mundo conectado. Rio de Janeiro: Zahar, 2011.

SILVA, Sandra R. "EU NÃO VIVO SEM CELULAR": Sociabilidade, Consumo, Corporalidade e Novas Práticas nas Culturas Urbanas. Intexto, Porto Alegre: UFRGS, v. 2, n. 17, p. 1-17, jul./dez. 2007.

TZANAKIS, M. Social capital in Bourdieu's, Coleman's and Putnam's theory: empirical evidence and emergent measurement issues. Educate , v. 13, n. 2, p. 2-23, 2013.

VANNINI, P. (ed.). Material Culture and Technology in Everyday Life: Ethnographic Approaches (Intersections in Communications and Culture: Global Approaches and Transdisciplinary Perspectives). New York: Peter Lang, 2009. 